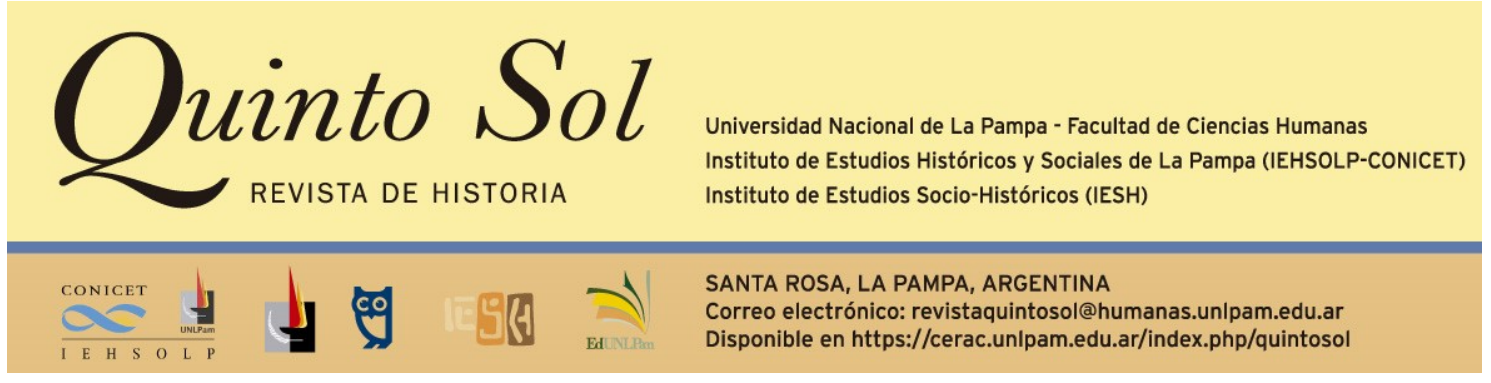

Quinto Sol, vol. 23, n 3, septiembre-diciembre 2019, ISSN 1851-2879, pp. 1-4

DOI: http://dx.doi.org/10.19137/qs.v23i3.3673

Esta obra se publica bajo licencia Creative Commons 4.0 Internacional. (Atribución-No ComercialCompartir lgual)

\title{
Irene López. Discursos identitarios en el folklore de Salta. Las producciones de Gustavo "Cuchi" Leguizamón y José Juan Botelli. Salta: Editorial de la Universidad Nacional de Salta, 2018, 323 páginas.
}

\author{
Fabiola Orquera \\ Consejo Nacional de Investigaciones Científicas y Técnicas \\ Universidad de Tucumán. Instituto de Investigaciones sobre el Lenguaje y la Cultura \\ Argentina \\ Correo electrónico: faorquera@gmail.com
}

El libro Discursos identitarios en el folklore de Salta. Las producciones de Gustavo "Cuchi" Leguizamón y José Juan Botelli, de Irene López, constituye un valioso aporte para los estudios sobre folklore y campos culturales de las provincias argentinas. La autora desarrolla sus actividades en la Universidad Nacional de Salta y en el Instituto de Ciencias Sociales y Humanidades, donde se desempeña como investigadora del Consejo Nacional de Investigaciones Científicas y Técnicas, institución que financió junto a la Agencia Nacional de Promoción Científica y Tecnológica- las becas doctorales en cuyos proyectos se basa la obra reseñada. Su formación, tanto en

\footnotetext{
${ }^{1}$ Leguizamón (1917-2000) nació en la ciudad de Salta. Fue abogado, fiscal de Estado en su provincia y diputado nacional. Se destacó en la música con composiciones de zambas, chacareras, carnavalitos y obtuvo varios premios, entre ellos recibió en 1985 el Premio Konex-Diploma al Mérito como uno de los cinco mejores compositores de folklore de la década. Botelli (1923-2010) también nació en la misma ciudad. Fue bandoneonista, pianista, compositor, profesor y escritor; compuso más de cien obras musicales y publicó una veintena de libros. Dirigió la página literaria del diario "El Tribuno" por tres décadas y fue director de Cultura de la provincia. En sus últimos años de su vida se dedicó a las artes plásticas con un estilo particular.
} 
literatura como en música, la llevó a explorar el rol de la canción de folklore en la construcción de identidades, temática sobre la que publicó diversos artículos, algunos junto a la antropóloga Andrea Villagrán.

El estudio que aquí presenta es posible entroncarlo a la corriente de investigaciones sobre folklore musical del noroeste, iniciadas a fines de la década de 1920, como parte del proceso de constitución de identidad regional inspirado en el criollismo. En ese momento, la élite azucarera tucumana costeó las actividades de recopilación y de análisis de expresiones ancestrales llevados a cabo por Juan Alfonso Carrizo e Isabel Aretz. Al mismo tiempo, Atahualpa Yupanqui inició sus extensos recorridos por el Ande $^{2}$ buscando formas musicales antiguas para estudiarlas y recrearlas. En los años cuarenta, Leda Valladares retomó la tarea de sus antecesores desde un lugar no disciplinario, siguiendo un profundo llamado a encontrarse con los cantos ancestrales. Esa actividad continuó a mediados de los sesenta, cuando Jorge Prelorán la invitó a musicalizar una serie de documentales antropológicos destinados a registrar antiguos oficios que sobrevivían en la región.

Con la reapertura de la etapa democrática se produjo un quiebre en el paradigma disciplinario vigente hasta entonces, iniciado por Augusto Raúl Cortazar y Carlos Vega, que concebía al folklore como un discurso oral, anónimo, colectivo y rural. El reposicionamiento dio importancia a las prácticas generadas en el espacio urbano, atravesado por los medios de comunicación, recurriendo a disciplinas como la sociología de la cultura y la historia. Desde esta nueva mirada, Ricardo Kaliman se interesó en reelaborar postulados de la sociología de Pierre Bourdieu de acuerdo con una perspectiva andinista del noroeste argentino y se ocupó de la identidad regional y el "folklore moderno", cuyo comienzo está marcado por Yupanqui. Por su parte, Claudio Díaz se remite a las proposiciones de Ricardo Costa y Teresa Mozejko para deslindar los paradigmas que permiten describir el desenvolvimiento del folklore nacional, al tiempo que analiza las prácticas musicales contemporáneas vinculadas a circuitos de folklore alternativo.

Desde los estudios que ponen el énfasis en la reconstrucción histórica, política y de trayectorias musicales, deben señalarse las investigaciones de Ariel Gravano sobre el folklore "de proyección" -término cuestionado desde las perspectivas renovadoras-; de Oscar Chamosa dedicadas a la conexión entre el movimiento folklórico, las élites azucareras y la conformación de la región en la primera mitad del siglo XX; de Radek Sánchez Patzy centradas en los músicos que atraviesan la frontera con Bolivia, uniendo las tradiciones musicales de este país y de Argentina; de Carlos Molinero sobre la canción militante en el folklore argentino; y de Fabiola Orquera en relación a la obra de Yupanqui, Pepe y Gerardo Núñez, Chivo y Leda Valladares. Al lado de esta corriente se deben mencionar indagaciones biográficas como las de Félix Luna, Fernando Boasso, Norberto Galasso y Sergio Pujol sobre Yupanqui; las entrevistas de Tcherkaski a Yupanqui y a Cuchi Leguizamón; las reconstrucciones de vida de Mercedes Sosa elaboradas por Rodolfo Braceli, Fabián Matus et al., Darío Marchini y Matthew Karusch; el libro de Adolfo "Bebe" Ponti sobre músicos dedicados a la chacarera en Santiago del Estero; y memorias como las de Juan Falú, que conectan la práctica estética a la función social y al trasfondo político del folklore. A este conjunto se suman investigaciones que provienen de la musicología, como las de Rubén Pérez Bugallo y Julius Carlson.

\footnotetext{
${ }^{2}$ En referencia a la cordillera de los Andes.
} 
En cuanto al campo cultural salteño, sus grupos poéticos y la figura del gaucho, vale destacar las contribuciones de Zulma Palermo, Alicia Chibán, Mercedes Castelaneli y Hernán Sosa, Susana Rodríguez, Víctor Arancibia y Alejandra Cebrelli, María Eugenia Carante, Ricardo Kaliman y Soledad Martínez Zuccardi; también los aportes de Arturo y José Juan Botelli, cuyas notas de periodismo cultural fueron parte de la reconstrucción del contexto en el que emergieron las obras seleccionadas.

En este panorama, el libro reseñado se ubica en el ámbito del análisis socio discursivo. Además de las referencias a las concepciones de Stuart Hall y Simon Frith, Irene López se apoya en investigaciones de Kaliman y Díaz sobre identidad en el folklore argentino, poniendo el acento en el carácter relacional y dinámico de esta categoría. Desde esta perspectiva, destaca que, a pesar de la relevancia de su producción, Leguizamón y Botelli no cuentan con obras de investigación que les estén íntegramente dedicadas.

En ese sentido, la autora comienza su trabajo planteando los lineamientos teóricos que orientan su mirada, presta particular atención a los dos polos de tensión que atraviesan la idea de "salteñidad", como son los opuestos tradición-renovación y música popular e ilustrada. En el segundo capítulo, se adentra en las condiciones de emergencia del corpus considerado, las configuraciones del campo cultural salteño y las concepciones de arte, cultura popular y música que animan los proyectos estéticos de Leguizamón y Botelli, mostrando sus diferencias. El capítulo siguiente, se enfoca en las construcciones discursivas del campo y los sujetos que lo habitan, sobre todo su figura emblemática, el gaucho, y los modelos antagónicos que asume: el "decente" versus el "rústico"; el norteño versus el centralista-mitrista; y el heroico, epitomizado por Martín Miguel de Güemes, versus el rebelde-bárbaro asociado a Facundo Quiroga, Felipe Varela y Pelayo Alarcón. Estas representaciones llevan a examinar las relaciones entre historia y ruralidad, para dar pie a un estudio minucioso de las composiciones, marcando las diferencias en los posicionamientos ideológicos de los autores y los poetas que colaboran con ellos: del lado de Botelli se ubican José Ríos, Guillermo Villegas y César Perdiguero, quienes se hacen eco del punto de vista de la élite salteña, mientras que junto a Leguizamón se planta Manuel J. Castilla, quien manifiesta disidencias con respecto al paradigma clásico, esencialista y la concepción hegemónica de "salteñidad".

El cuarto capítulo, está dedicado a la representación del mundo del trabajo, la reinterpretación de leyendas de circulación oral y la incorporación de acontecimientos políticos significativos, particularmente en las décadas del sesenta y setenta, cuando los poetas salteños se vinculan a los integrantes del Movimiento Nuevo Cancionero. El análisis se centra en la conversión de algunos personajes de zambas de Castilla en héroes populares, como Don Balta, Juan Riera, Juan Ponce, Maturana y Eulogia Tapia. La crítica a situaciones de desigualdad social y marginalidad se expresan sutilmente en estos retratos y se acerca a la posición de izquierda, dominante en el campo en las décadas señaladas, aunque sin que se manifieste una militancia abierta. Más que una exhortación a la lucha colectiva, se canta al sufrimiento de las personas retratadas. López contrasta además las elaboraciones de Castilla con las de José Ríos y Jaime Dávalos, al tiempo que advierte una configuración del sujeto colectivo en la Zamba del imaginero de Armando Tejada Gómez, enmarcada en el ideario del Movimiento Nuevo Cancionero. Este horizonte también se hace presente en Lavanderas del Río Chico y Chacarera del expediente, de Leguizamón y en Chacarera de la Patria Financiera, de 
Nella Castro.

El quinto capítulo, se ocupa de la representación de cantores y sus prácticas, al tiempo que se explaya en el análisis del lugar del artista y la concepción del fenómeno musical en los ámbitos de la música popular y letrada. Por último, las conclusiones concentran y refuerzan la investigación realizada a lo largo del libro, subrayando que la selección del corpus abordado no fue casual, sino que se debió a la importancia que adquirieron estas composiciones en la formación de la imagen de "salteñidad" y la masividad que alcanzaron. López también destaca su interés en marcar los "rasgos de ilustración" y la "voluntad popular" en el conjunto de autores considerados. Como cierre, el libro incluye una serie de fotografías del archivo de la familia Botelli que ilustran la participación de los folkloristas a los que se dedica el libro en escenas de la vida musical salteña, más un anexo con el conjunto de canciones examinadas.

La autora consigue así los objetivos que se había propuesto: contribuir a la reconstrucción del campo artístico y musical de Salta, y mostrar la importancia de la dimensión simbólica del cancionero considerado en el proceso de formación de identidades. Más aún, el alcance de Discursos identitarios en el folklore de Salta trasciende el ámbito académico de esta provincia, porque fortalece los estudios sobre el campo cultural del noroeste y el folklore argentino. 